\title{
Measurement-based electrical parameters of power transformers for Frequency Response Analysis interpretation - Part I: Core analysis
}

\author{
Dinh Anh Khoi Pham
}

\begin{abstract}
Although the standard Frequency Response Analysis (FRA) test has been approved as an efficient tool to diagnose mechanical failures in power transformers, the demand to interpret FRA traces in practical and physical way is still requested. That means physical electrical parameters of transformers should be determined reasonably based on real measurements and afterwards are applicable for the interpretation.

For purpose of FRA interpretation in practical manner, electrical parameters of power transformers in a physical equivalent circuit should be determined. As a first step, the paper introduces a new approach in determining frequency dependent core impedances of a distribution transformer based on the combination of circuit analysis of a duality-based model, measurements of driving-point impedances and experimental formulas. From that, two important contributions can be drawn. Firstly, frequency dependent core impedances are ready as available components in the circuit for FRA interpretation in broad frequency range. Secondly, the core parameters could be useful indicators for detecting relevant failures in cases there is no more failure on transformer windings.
\end{abstract}

Index Terms-Driving-point impedance, duality principle, electrical parameters, frequency response analysis, transformer core.

\section{INTRODUCTION}

$\mathrm{T}$ The core is an important component of power transformers, which provides magnetic links between the windings. Its magnetic property has been so far investigated in detail through

Manuscript Received on March 15 ${ }^{\text {th }}$, 2017, Manuscript Revised on November $01^{\text {st }}, 2017$.

Dinh Anh Khoi Pham, Division of High-Voltage Engineering, Department of Power Systems, Faculty of Electrical and Electronic Engineering, Ho Chi Minh City University of Technology, VNU-HCM, Vietnam (e-mail: khoipham@hcmut.edu.vn). measurements and design data based simulations [1]. However, the dual electrical equivalence of the core is still not widely approved for FRA investigations since it has been understood that the core does not play any key role in analysis of frequency responses of power transformers in medium and high frequency range. Nevertheless, it is realized that electrical impedances of core sections are necessary in determination of influence of the immeasurable winding series capacitance on total capacitance effect of the transformers, which will be mentioned in the Part II [2]. In addition, in several cases the zerosequence impedance representing flux paths outside the windings is important at medium frequencies; as a result, a transformer circuit with physical dual magnetic-electrical core representation should be in general investigated.

In order to introduce a practical approach in analysis of the transformer core for purpose of FRA interpretation in low and medium frequency range, this paper introduces a new approach in determining frequency dependent core parameters. Two important contributions of the paper can be drawn: the applicability of the approach for any transformer, and the availableness of frequency dependent core impedances in broad frequency range for the feasibility of FRA interpretation via circuit simulation.

A test opened transformer with rating $\begin{array}{llllll}\text { parameters } 200 & \mathrm{kVA} & 10.4 / 0.46 & \mathrm{kV} & \text { YNyn6 }\end{array}$ transformer is then investigated in this paper. Core section impedances of the transformer are analyzed based on measurements of frequency responses of open-circuit driving-point impedances at the high-voltage (HV) side at low frequencies. (Core impedances at the low-voltage (LV) side are not investigated due to their very low values). The measurements are performed by 
mean of a commercial scattering-parameter vector-network analyzer (VNA) with chosen settings appropriate for FRA purpose: open-circuit voltage of $1 \mathrm{~V}_{\mathrm{rms}}$, broad frequency range from 20 $\mathrm{Hz}$ to $2 \mathrm{MHz}$ with 801 points, receiver bandwidth of $30 \mathrm{~Hz}$.

\section{REVIEW OF THE DUALITY-BASED LUMPED TRANSFORMER CIRCUIT}

This section recalls the duality-based transformer circuit that is originally developed for the purpose of transient and frequency response analysis [3, 4]. In this paper, only inductive components such as core, leakage and zerosequence impedances appear in the circuit since the circuit is then analyzed at low frequencies to determine the core impedances. For the complete investigation at low and medium frequencies, the full circuit with appearance of winding capacitances will be introduced in the Part II [2].

Fig. 1 depicts the duality-based equivalent circuit of the test transformer in low frequency range with three per-phase zero-sequence impedances and one leakage inductance in context of an open-circuit driving-point impedance test performed on the $\mathrm{HV}$ winding of phase $\mathrm{A}$ by means of the VNA. In Fig. $1, \mathrm{Z}_{1}=\mathrm{R}_{1} / / \mathrm{L}_{1}, \mathrm{Z}_{\mathrm{y}}=$ $\mathrm{R}_{\mathrm{y}} / / \mathrm{L}_{\mathrm{y}}$ are non-linear core leg and yoke impedances respectively; $\mathrm{L}_{3}$ are (per-phase) leakage inductances; $\mathrm{Z}_{4}=\mathrm{R}_{4} / / \mathrm{L}_{4}$ are per-phase zero-sequence impedances; $\mathrm{R}_{\mathrm{H}}$ and $\mathrm{R}_{\mathrm{L}}$ are resistances of $\mathrm{HV}$ and $\mathrm{LV}$ windings. All of them are frequency dependent. $\mathrm{N}_{\mathrm{H}}: \mathrm{N}_{\mathrm{L}}$ is the transformer ratio.

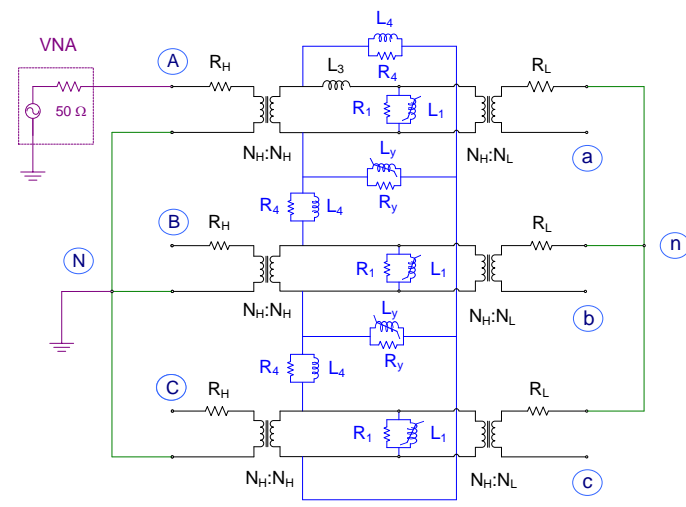

Fig. 1. Lumped circuit of the test transformer in a single-phase impedance measurement at $\mathrm{HV}$ side at low frequencies.

\section{MeAsurement-Based Determination PROCEDURE OF TRANSFORMER CORE IMPEDANCES AT LOW FREQUENCIES}

In this section, a new procedure in determining core impedances $\left(\mathrm{Z}_{1}, \mathrm{Z}_{\mathrm{y}}\right)$ based on measurements of open-circuit driving-point impedances on star winding in low frequency range is proposed. The low frequency range that is different with different transformers is defined within $20 \mathrm{~Hz}$ to a frequency where the measured impedances are still purest inductive.

\subsection{Necessary measurement configurations}

Since core influence is dominant in open-circuit impedances at low frequencies, it is logical to analyze only core impedances that are referred into $\mathrm{HV}$ side in the equivalent circuit in Fig. 1 $\left(\mathrm{R}_{\mathrm{H}}, \mathrm{L}_{3}\right.$, and $\mathrm{Z}_{4}$ are short-circuited, $\mathrm{R}_{\mathrm{X}}$ has no influence, the LV phase windings are left open).

In order to determine core impedances, different configurations of open-circuit measurements associated with different core impedance combinations shown in Table 1 are necessary. In Table 1, equivalent impedances are input impedances seen from the excited terminals. Afterwards, a data fitting procedure is applied to determine the core impedances with a selected number of measurement configurations.

TABLE 1

CONFIGURATIONS OF INPUT IMPEDANCE MEASUREMENTS ON STAR WINDING

\begin{tabular}{ccl}
\hline \hline No & \multicolumn{1}{c}{ Configuration } & \multicolumn{1}{c}{ Calculated $\mathrm{Z}_{\text {equivalent }}$} \\
\hline 1 & A-N excited (in Fig. 1) & $\left(\mathrm{Z}_{1} / / \mathrm{Z}_{\mathrm{y}}+\mathrm{Z}_{1}\right) / /\left(\mathrm{Z}_{1} / / \mathrm{Z}_{\mathrm{y}}\right)$ \\
2 & A-N excited, B-N shorted & $\left(\mathrm{Z}_{1} / / \mathrm{Z}_{\mathrm{y}}\right) / /\left(\mathrm{Z}_{1} / / / \mathrm{Z}_{\mathrm{y}}\right)$ \\
3 & A-N excited, C-N shorted & $\mathrm{Z}_{1} / /\left(\mathrm{Z}_{1} / / \mathrm{Z}_{\mathrm{y}}\right)$ \\
4 & B-N excited & $\left(\mathrm{Z}_{1} / / / \mathrm{Z}_{\mathrm{y}}+\mathrm{Z}_{1} / / \mathrm{Z}_{\mathrm{y}}\right) / / \mathrm{Z}_{1}$ \\
5 & B-N excited, C-N shorted & $\left(\mathrm{Z}_{1} / / \mathrm{Z}_{\mathrm{y}}\right) / / \mathrm{Z}_{1}$ \\
6 & B-N excited, A-N shorted & $\left(\mathrm{Z}_{1} / / \mathrm{Z}_{\mathrm{y}}\right) / / \mathrm{Z}_{1}$ \\
7 & C-N excited & $\left(\mathrm{Z}_{1} / / \mathrm{Z}_{\mathrm{y}}+\mathrm{Z}_{1}\right) / /\left(\mathrm{Z}_{1} / / \mathrm{Z}_{\mathrm{y}}\right)$ \\
8 & C-N excited, B-N shorted & $\left(\mathrm{Z}_{1} / / \mathrm{Z}_{\mathrm{y}}\right) / /\left(\mathrm{Z}_{1} / / \mathrm{Z}_{\mathrm{y}}\right)$ \\
9 & C-N excited, A-N shorted & $\mathrm{Z}_{1} / /\left(\mathrm{Z}_{1} / / \mathrm{Z}_{\mathrm{y}}\right)$ \\
\hline \hline
\end{tabular}

\subsection{Data fitting procedure}

The procedure is designed to solve a mathematic problem with two non-linear variables $\left(\mathrm{Z}_{1}\right.$ and $\mathrm{Z}_{\mathrm{y}}$ ) based on measurement configurations in Table 1 . The problem can be solved efficiently through a non-linear least-square solver whose objective function is established as norm of real and imaginary impedance errors.

In Table 1, there are nine different measurement configurations and four different calculated equivalent impedances. That means, to determine reasonable core impedances, at least 
two configurations that have different calculated equivalent impedances should be taken into account. In fact, the best solution is using all configurations for data fitting.

To prove this argument, the so-called maximum magnitude error $\Delta \mathrm{Z}_{\max }$ between measured and calculated impedances introduced in Table 1 is determined for two cases: a) three first configurations of measurements on phase A and $b)$ all nine configurations are analyzed. The $\Delta \mathrm{Z}_{\max }$ is of the $4^{\text {th }}$ configuration in Table 1 (B-N excited) with values of $10.29 \%$ (case a) and $1.45 \%$ (case b). Obviously, analysis of all measurement configurations provides better results, which cannot be achieved by using measurements on a single phase as proposed in the approach in [4].

\subsection{Influence of zero-sequence impedances}

It is realized that per-phase zero-sequence impedances have small but certain influence on core analysis at frequency from $20 \mathrm{~Hz}$ to $100 \mathrm{~Hz}$ for the test transformer due to their high values since the transformer has no tank. The calculation of equivalent impedances is still based on analysis of the circuit in Fig. 1 but not presented due to its complexity. Fig. 2 plots fundamental parameters of core sections $\left(\mathrm{R}_{1}, \mathrm{R}_{\mathrm{y}}, \mathrm{L}_{1}, \mathrm{~L}_{\mathrm{y}}\right)$ in frequency range from $20 \mathrm{~Hz}$ to $400 \mathrm{~Hz}$ calculated from the core impedances $\left(Z_{1}, Z_{y}\right)$ of the test transformer when two zero-sequence impedances of outer phases are considered. In general, when transformers have tank, influence of other components than core impedances can be neglected at low frequencies.

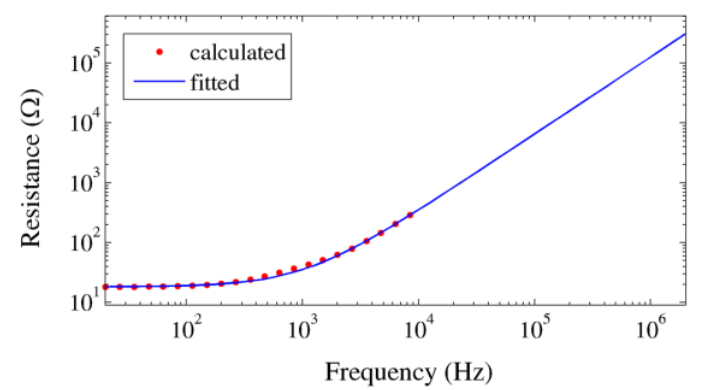

Fig. 2. Core section components calculated from $20 \mathrm{~Hz}$ to $400 \mathrm{~Hz}$.

\section{Formula-Based Determination Procedure OF TRANSFORMER CORE IMPEDANCES AT HIGH FREQUENCIES}

In this section, only the core impedances of the test transformer are calculated based on formulas since as frequency is higher than $400 \mathrm{~Hz}$, core impedances of the test transformer are no longer dominant in measured open-circuit impedances. Since the main goal of the research is to interpret FRA measurements, all inductive impedances in the equivalent circuit should be developed versus frequency in broad frequency range. This section will discuss how the core impedances are determined at frequencies higher than $400 \mathrm{~Hz}$ for application.

\subsection{Phenomena in transformer core at low field applied in the FRA measurements}

1) Eddy current (skin effect): It is a main effect caused by low alternating magnetic field within transformer core laminations. When such magnetic field generated by frequency-varying source penetrates a ferromagnetic material, induced circulating current loops appear and are called as eddy currents whose density has a nonlinear distribution depending on frequency of the magnetic field. As a result, a non-linear distribution of magnetic flux (towards the surface) is associated. This phenomenon results in the socalled eddy current loss which brings a rise of effective resistance and a reduction of inductance when frequency increases $[1,5]$. Eddy current loss is proportional to the square of lamination thickness, square of frequency and square of effective value of flux density [6].

2) Hysteresis phenomenon: It is a characteristic of a magnetic material to retain magnetization or to oppose a change in magnetization, which depends on applied magnetic field magnitude. When a low field is applied, there is reversible change in domain magnetic structures which causes the magnetization returns to its initial value on removal of the external magnetic field. As field strength is high enough for the so-called magnetic domain wall motion, both reversible and irreversible processes take place so that the magnetization does not return to its original value on applied filed removal [1]. In case applied field is cyclic and its magnitude is high enough, there exists a hysteresis (B-H) loop whose loss is proportional to the area of the B-H loop [6]. However, under a low applied field for FRA measurements $(\sim 1 \mathrm{~V})$, the corresponding hysteresis loop is a small elliptical loop whose area is very small and therefore, hysteresis loss is considered insignificant compared with eddy current loss at high frequencies [1].

3) Anomalous losses: There exists another 
complicated phenomenon in the core which is called as diffusion effect in the crystal grid (domain structures) of the core material causing anomalous losses [7].

Conclusion: Under low field and no-load conditions, the (classical) skin effect has most influence whereas other phenomena can be neglected [1]. From that, core impedances are determined based on relevant experimental formulas.

\subsection{Calculation of core impedances based on skin effect}

1) Magnetic reluctance: The reluctance of the core (leg) section in the magnetic circuit representing a relation between the magnetomotive force $\mathrm{F}$ and corresponding flux $\Phi$ can be determined based on magnetic and design parameters of the core as follows $[8,9]$ :

$$
\mathfrak{R}=\frac{\mathrm{F}}{\Phi}=\frac{\ell}{\hat{\mu}_{\mathrm{eff}} \mu_{0} \mathrm{~A}}
$$

where $\ell(\mathrm{m})$ is the magnetic flux path length of the core section; $\hat{\mu}_{e f f}$ is the complex effective relative permeability of core lamination in rolling direction, i.e., along the core section; $\mu_{0}(\mathrm{H} / \mathrm{m})$ is the permeability constant of free space and $\mathrm{A}\left(\mathrm{m}^{2}\right)$ is the cross-sectional area of the core section.

The complex effective relative permeability $\hat{\mu}_{e f f}$ in the rolling direction of the magnetic flux is expressed as $[1,10]$ :

$$
\hat{\mu}_{e f f}=\mu_{e f f}^{\prime}-j \mu_{e f f}^{\prime \prime}=k_{f e} \mu_{r} \frac{\tanh \{(1+j) b / \delta\}}{(1+j) b / \delta}
$$

where $k_{f e}$ is stacking factor representing fraction of core steel in the total cross section, $\mu \mathrm{r}$ is local relative permeability in the rolling direction, $b(\mathrm{~m})$ is half of a lamination thickness and $\delta(\mathrm{m})$ is skin depth or depth of penetration of eddy currents.

The skin depth $\delta$ is frequency dependent and calculated as [5]:

$$
\delta=\sqrt{2 /\left(\omega \sigma \mu_{0} \mu_{r}\right)}
$$

where $\omega(\mathrm{radian} / \mathrm{s})$ is angular frequency and $\sigma$ $(\mathrm{S} / \mathrm{m})$ is the electrical conductivity of the core lamination.

2) Dual electrical impedance: The complex reluctance $\mathfrak{R}$ accounting for skin effect has a dual electrical impedance $\mathrm{Z}$ whose equivalent circuit consists of a resistance $\left(R_{s}\right)$ in series with an inductance $\left(\mathrm{L}_{\mathrm{s}}\right)[8]$ :

$$
Z=j \omega N^{2} \frac{1}{\Re} \equiv R_{s}+j \omega L_{s}
$$

where $\mathrm{N}$ is the number of turns of the excited winding on the phase of the core section.

From that, the resistance $R_{s}(\Omega)$ and inductance $\mathrm{L}_{\mathrm{s}}(\mathrm{H})$ can be determined as:

$$
\begin{aligned}
\mathrm{R}_{\mathrm{s}} & =-\omega \mathrm{N}^{2} \operatorname{Im}\{1 / \mathfrak{R}\} \\
\mathrm{L}_{\mathrm{s}} & =\mathrm{N}^{2} \operatorname{Re}\{1 / \mathfrak{R}\}
\end{aligned}
$$

Due to the fact that the equivalent electrical circuit of a core section in Fig. 1 includes only resistance and inductance in parallel, $\mathrm{R}_{\mathrm{s}}$ and $\mathrm{L}_{\mathrm{s}}$ should be converted into $R_{p}$ and $L_{p}$ respectively.

3) Calculation of core impedance: Thanks to the magnetic parameters which can be in general applied for a transformer core $[1,10]$ and approximate design parameters of the core leg of the test transformer in Table 2, components of the core leg in both series and parallel models are derived and shown in Fig. 3. A comparison between the measurement- and formula-based components of the core leg at the so-called joint frequency, i.e. $400 \mathrm{~Hz}$, in Fig. 2 and 3 respectively shows that there is small error between $\mathrm{L}_{1}$ and $\mathrm{L}_{\mathrm{p}}$, which indicates that the calculation of a core section based on skin effect is acceptable and therefore can be used at high frequencies. Error between $R_{1}$ and $R_{p}$ at $400 \mathrm{~Hz}$ is not important since it contributes only to a little change of damping of frequency responses at first resonance frequencies.

TABLE 2

MAGNETIC AND DESIGN PARAMETERS FOR CORE IMPEDANCE CAlculation

\begin{tabular}{lll}
\hline \hline $\begin{array}{l}\text { Para- } \\
\text { meter }\end{array}$ & \multicolumn{1}{c}{ Quantity } & \multicolumn{1}{c}{ Value } \\
\hline$\mu_{0}$ & permeability of free space & $4 \pi \times 10^{-7} \mathrm{H} / \mathrm{m}$ \\
$\mu_{\mathrm{r}}$ & relative permeability & 500 \\
$\sigma$ & conductivity & $5 \times 10^{6} \mathrm{~S} / \mathrm{m}$ \\
$2 b$ & lamination thickness & $0.35 \times 10^{-3} \mathrm{~m}$ \\
$\mathrm{k}_{\mathrm{fe}}$ & stacking factor & 0.92 \\
$\ell$ & core section length & $0.36 \mathrm{~m}$ \\
$A$ & core cross-sectional area & $25.6 \times 10^{-3} \mathrm{~m}^{2}$ \\
$N$ & number of turns & $736 \mathrm{turns}$ \\
\hline \hline
\end{tabular}




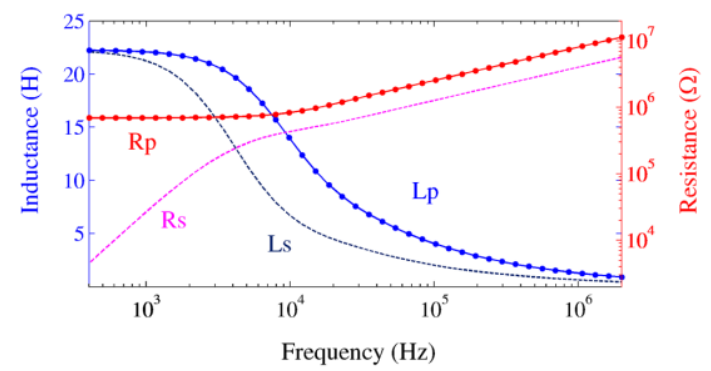

Fig. 3. Skin-effect-based core leg components from $400 \mathrm{~Hz}$ to $2 \mathrm{MHz}$.

\section{Frequency DePENDENT CoRe PARAMETERS}

The frequency dependent functions of core parameters (resistances, inductances) in broad frequency range can be obtained from measured values (at low frequencies) and calculated values (at high frequencies), simply by combining the fitting functions [11] of parameter values in whole frequency range. The fitting functions yield smooth representation of measurement based values (see Fig. 2) and can be used to adapt the formula based values (see Fig. 3) so that there is no difference between them at the joint frequency. Fig. 4 and 5 plot frequency dependent functions of inductances and resistances of core legs and yokes in broad frequency range.

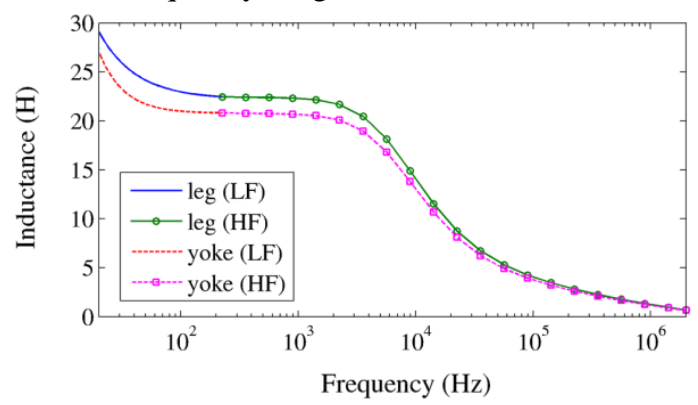

Fig. 4. Core section inductances from fitted frequency dependent functions.

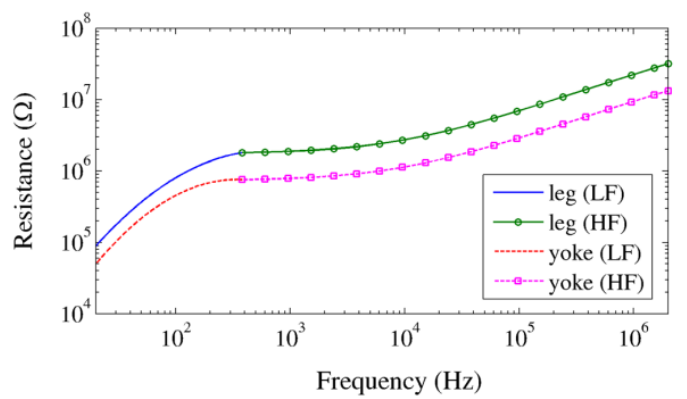

Fig. 5. Core section resistances from fitted frequency dependent functions.

It is realized in Fig. 4 that core inductances vary significantly at very low frequencies, e.g., from $20 \mathrm{~Hz}$ to $100 \mathrm{~Hz}$. It is not clear whether the changes at such frequencies come from the transformer core itself (saturation condition) or from the measurement system. In the measurement system, the problem may be caused by the difference of characteristic impedances of the measuring cable (not $50 \Omega$ from $20 \mathrm{~Hz}$ to several tens $\mathrm{kHz}$ ) and the instrument source $(50 \Omega)$ since the measurement is performed by means of the VNA. However, a good measurement with a known resistance in broad frequency range after calibration shows that the calibration removes the effect very well. It is concluded that, for the purpose of FRA application, the parameter functions plotted in Fig. 4 and 5 can be used in whole frequency range.

\section{CONCLUSION}

This paper presents a complete approach in determining core section impedances of a distribution transformer in a duality-based circuit based on measurements of frequency responses of driving-point impedances at low frequencies and skin-effect-based formulas at high frequencies. Several important contributions of the paper can be drawn as follows.

Physical electrical parameters of two-winding three-legged transformers are introduced in the duality-based circuit for the purpose of FRA interpretation at low and medium frequencies. As a first step, frequency dependent functions of core parameters in whole range of frequencies are determined and ready as available components for simulation.

Formula-based calculation of core parameters of the test transformer at high frequencies is proposed since the parameters cannot be determined directly from measurements at these frequencies. More importantly, the formula-based solution provides "reference curves" from which core impedances of any transformer can be obtained reasonably in broad range of frequencies based on only the measurements at low frequencies. This contributes to large application for FRA purpose.

The calculated constant values of core parameters at a "joint frequency" can be used as physical indicator to diagnose core problem. It is suggested from the research that core parameters should be calculated based on the proposed approach as "fingerprint" data when transformers 
are in healthy condition for any comparison later.

\section{REFERENCES}

[1] Abeywickrama N., Serdyuk Y. V., and Gubanski S. M., "High-Frequency Modeling of Power Transformers for Use in Frequency Response Analysis," IEEE Transactions on Power Delivery, vol. 23, no. 4, pp. 2042-2049, Oct. 2008.

[2] D.A.K. Pham, "Measurement-based electrical parameters of power transformers for FRA interpretation-Part II: Winding analysis," to be sent to the Journal of Science and Technology Development, VNU-HCM, 2017.

[3] B. A. Mork, Francisco Gonzalez, Dmitry Ishchenko, Don L. Stuehm, and Joydeep Mitra, "Hybrid transformer model for transient simulation-Part I: Development and parameters," IEEE Transactions on Power Delivery, vol. 22, no. 1, pp. 248-255, 2007.

[4] B. A. Mork, Francisco Gonzalez, Dmitry Ishchenko, Don L. Stuehm, and Joydeep Mitra, "Hybrid transformer model for transient simulation - Part II: Laboratory measurements and benchmarking," IEEE Transactions on Power Delivery, vol. 22, no. 1, pp. 256-262, 2007.

[5] J. Lammeraner, and M. Stafl, Eddy currents, Iliffe Books Ltd., London 1960, ch. 2.

[6] S. V. Kulkarni, and S. A. Khaparde, Transformer engineering design and practice, Marcel Dekker, 2004, ch. 3 .

[7] ABB, Transformer Handbook, 3rd Ed., 2007.

[8] E Colin Cherry, "The duality between interlinked electric and magnetic circuits and the formation of transformer equivalent circuits," Proceed. of the Phy. Soc., Section B, vol. 62, no. 2, pp. 101-111, 1949.

[9] L. Dixon, "Deriving the equivalent electrical circuit from the magnetic device physical properties," Texas Ins. Document, Oct. 1994 (available at http://www.ti.com/lit/m1/slup198/slup198.pdf)

[10] A. Shintemirov, W. H. Tang, and Q. H. Wu, "Transformer core parameter identification using frequency response analysis," IEEE Transactions on Magnetics, vol. 46, no. 1, pp. 141-149, 2010.

[11] Mathwork Inc., Curve fitting toolbox.

Dinh Anh Khoi Pham was born in Ninh-Thuan, Vietnam, in 1979. He received the B.Sc. and M.Sc. in electrical engineering from the Ho Chi Minh City University of Technology, VNU-HCM in 2002 and 2004, respectively, and the Ph.D. degree in electrical engineering from the Leibniz Universität Hanover, Germany in 2013. Since 2014 he has worked as Lecturer at the Ho Chi Minh City University of Technology, VNU-HCM, Vietnam. His research interest includes simulation, testing and diagnostics of power transformers.

\title{
Thông số điện máy biến áp lực cho phân tích đáp ứng tần số - Phần I: Lõi thép
}

\author{
Phạm Đình Anh Khôi
}

Tóm tắt- Mặc dù các phép đo đáp ứng tần số đã được áp dụng hiệu quả trong việc chẩn đoán các sự cố cơ trong máy biến áp lực (MBA), cách thức phân tích kết quả đo trong thực tế vẫn chưa được đề xuất cụ thể, vốn cần phải dựa trên việc xác định các thông số điện của MBA từ các phép đo.

Để phân tích đáp ứng tần số ứng dụng thực tế, các thông số điện trong một sơ đồ mạch tương đương của MBA cần phải được xác định. Bài báo giới thiệu một giải pháp mới xác định tổng trở lõi thép theo tần số của một MBA phân phối dựa trên sự kết hợp giữa phép phân tích mạch tương đương MBA xây dựng trên nguyên lý tương hỗ, các phép đo tổng trở đầu cực và các công thức thực nghiệm. Kết quả của nghiên cứu là giá trị các tổng trở của lõi thép MBA nhận được trong vùng tần số rộng áp dụng cho phân tích đáp ứng tần số. Giá trị tổng trở này có thể ứng dụng để chẩn đoán sự cố của riêng lõi thép, trong trường hợp MBA không có các sự cố khác trên cuộn dây.

Tù khóa- Tổng trở đầu cực, nguyên lý tuơng hỗ, thông số điện, phân tích đáp ưng tần số, lõi thép máy biến áp. 